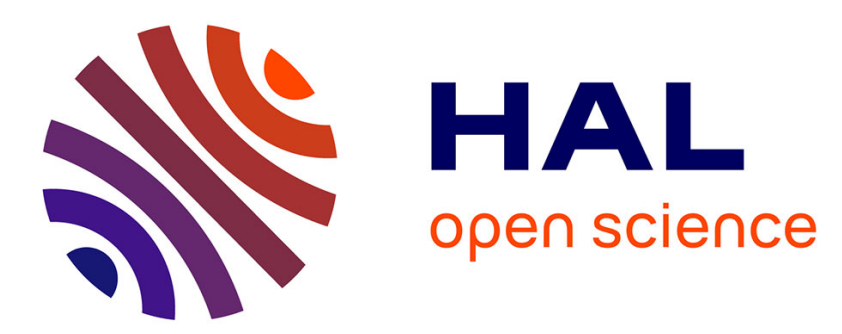

\title{
Flight path tracking based-on direct adaptive sliding mode control
}

Hakim Bouadi, Hongying Wu, Felix Mora-Camino

\section{To cite this version:}

Hakim Bouadi, Hongying Wu, Felix Mora-Camino. Flight path tracking based-on direct adaptive sliding mode control. IV 2011, IEEE Intelligent Vehicles Symposium, Jun 2011, Baden-Baden, Germany. pp 25-30, 10.1109/IVS.2011.5940395 . hal-00938420

\section{HAL Id: hal-00938420 \\ https://hal-enac.archives-ouvertes.fr/hal-00938420}

Submitted on 20 Jun 2014

HAL is a multi-disciplinary open access archive for the deposit and dissemination of scientific research documents, whether they are published or not. The documents may come from teaching and research institutions in France or abroad, or from public or private research centers.
L'archive ouverte pluridisciplinaire HAL, est destinée au dépôt et à la diffusion de documents scientifiques de niveau recherche, publiés ou non, émanant des établissements d'enseignement et de recherche français ou étrangers, des laboratoires publics ou privés. 


\title{
Flight Path Tracking Based-on Direct Adaptive Sliding Mode Control
}

\author{
Hakim Bouadi, H.Wu and F.Mora-Camino
}

\begin{abstract}
Adaptive control algorithms are of interest in the flight control systems design not only for their capability to improve performance and reliability but also for handling aerodynamic parameter uncertainties, external disturbances and modeling inaccuracies. This paper addresses a nonlinear direct adaptive sliding mode controller to perform a flight path tracking for a transportation aircraft. The synthesis of the adaptation laws is based on the positivity and Lyapunov design principle. Simulation results for different flight conditions for transportation aircraft are provided to illustrate the effectiveness of the proposed controller.
\end{abstract}

\section{INTRODUCTION}

The application of modern flight control design methodologies to transportation aircraft is currently limited by the complexity of the problem and the need of extensive testing to validate the proposed solutions mainly when conventional gain scheduling is involved. Also, any control methodology proposed for transportation aircraft should enable people to safely fly without requiring increased workload from the pilots. In this context, nonlinear adaptive control could be a promising way to design improved solutions to this problem since these techniques try to compensate for modeling inaccuracies and external disturbances; this is why many studies [1], [2], [4], [5], [6], [7], [8], [9], [10], [11]-[12] have been performed in this field.

In this paper, is proposed a new nonlinear direct adaptive sliding mode controller to ensure flight path tracking by a transportation aircraft.

The proposed controller is a combination of nonlinear dynamic inversion and sliding mode approach and it is synthesized in two steps; the first one consists in performing consecutive time derivatives of the considered output until the control input appears and the resulting equation is put under a linearly parameterized form while the second step consists in defining a sliding surface, a function of the tracking error and its time derivatives; then a Lyapunov function is chosen in order to extract the control law which verifies both asymptotic Lyapunov stability and sliding conditions.

\footnotetext{
Manuscript received December 23; 2010.This work was supported by Automation and Operational Research Laboratory of Air Transportation Department in the National Civil Aviation Institute in Toulouse-France.

H. Bouadi is $\mathrm{PhD}$ student and he is with the Automation and Operational Research Laboratory (LARA) in the National Civil Aviation Institute-ENAC; 07, Avenue Edouard Belin, 31400-ToulouseFrance (phone: +33 (0)-6-01-18-83-91; fax: +33 (0)-5-62-17-40-23 hakimbouadi@yahoo.fr, Hakim.Bouadi@enac.fr

$\mathrm{H}$. Wu is $\mathrm{PhD}$ student and she is with the Automation and Operational Research Laboratory (LARA) in the National Civil Aviation Institute-ENAC Hongying. Wu@enac. fr

F. Mora-Camino is Professor at the National Civil Aviation Institute and he is the director of the Automation and Operational Research Laboratory (LARA) at Air Transportation Department moracaminodhotmail. fr
}

Developed controller guarantees a good robustness against modelling parameter uncertainties while keeping the angle of attack $\alpha$ within an acceptable range. The synthesis of the adaptation mechanism is based on the positivity and Lyapunov design principle in order to estimate the controller parameters directly while the exponentially asymptotic convergence of the chosen sliding surface $\sigma$ is shown.

First are presented the vertical flight-path angle dynamics for a transportation aircraft while the controllability condition is checked.

A sliding surface $\sigma$ is chosen with respect to the relative degree of the considered output, flight path angle, and a control law is synthesized based on the sliding mode approach. Subsequently, the positivity and Lyapunov design principle is used to determine adaptation laws which ensure an exponentially asymptotic convergence of the closed-loop dynamics.

Finally, through simulation the performance of the proposed adaptive controller are studied with several flight conditions for a transportation aircraft.

\section{FLIGHT DYNAMICS MODELING}

Considering classical simplifying assumptions, the vertical flight equations adopted here are given by:

$$
\begin{gathered}
\dot{V}=\frac{1}{m}[T \cos (\alpha+i)-D-m g \sin (\gamma)] \\
\dot{\gamma}=\frac{1}{m V}[T \sin (\alpha+i)+L-m g \cos (\gamma)] \\
\dot{q}=\frac{M}{I_{y y}} \\
\dot{\theta}=q
\end{gathered}
$$

where $\gamma, V, \alpha$ and $i$ are respectively the flight path angle, the true airspeed, the angle of attack and the incidence angle of the thrust vector with respect to the centerline. $\theta, q$ and $M$ represent the pitch angle, the pitch rate and the pitch moment, respectively. $g$ is the gravity acceleration and $I_{y y}$ is the inertial moment around the pitch axis. $L$ and $D$ denote lift and drag forces, respectively.

$$
\begin{gathered}
M=\frac{1}{2} \rho V^{2} S \bar{c} C_{M} \\
C_{M}=C_{m_{\alpha}} \alpha+\frac{q \bar{c}}{2 V} C_{m_{q}}+C_{m_{\delta_{e}}} \delta_{e}
\end{gathered}
$$

where $C_{M}, \rho, S, \bar{c}$ and $\delta_{e}$ represent the pitching moment coefficient, the air density, the wing reference surface area, the mean chord line and the elevator deflection, respectively.

$C_{m_{\alpha}}, C_{m_{q}}$ and $C_{m_{\delta_{e}}}$ are non-dimensional stability derivatives and they denote respectively the change in the pitching 
moment coefficient with respect to the angle of attack, the change in the pitching moment coefficient with respect to the pitch rate and the elevator control effectiveness.

Lift force is expressed as follows:

$$
\begin{aligned}
L & =\frac{1}{2} \rho V^{2} S C_{L} \\
C_{L} & =C_{L_{0}}+C_{L_{\alpha}} \alpha
\end{aligned}
$$

where $C_{L}, C_{L_{0}}$ and $C_{L_{\alpha}}$ represent the lift coefficient, the reference lift coefficient and the lift curve slope respectively.

Since $\alpha=\theta-\gamma$ then:

$$
\dot{\alpha}=q-\frac{1}{m V}[T \sin (\alpha+i)+L-m g \cos (\gamma)]
$$

Here it is considered that at cruise, the true airspeed (TAS) is taken as a constant for a short period and the thrust term $T \sin (\alpha+i)$, is neglected as it is generally much smaller than lift [4]. Then, the longitudinal motion dynamics can be written under the nonlinear affine state representation as follows:

$$
\dot{x}=f(x)+g(x) u
$$

with:

$$
f(x)=\left(\begin{array}{c}
a_{1} \cos (\gamma)+a_{2}(\theta-\gamma)+\varepsilon_{\gamma} \\
q \\
a_{3} q+a_{4}(\theta-\gamma)
\end{array}\right), g(x)=\left(\begin{array}{l}
0 \\
0 \\
b
\end{array}\right)
$$

where: $x=[\gamma, \theta, q]^{T}, u=\delta_{e}$ and:

$$
\begin{aligned}
a_{1} & =-\frac{g}{V} & a_{2} & =\frac{1}{2 m} \rho V S C_{L_{\alpha}} \\
a_{3} & =\frac{1}{4 I_{y y}} \rho V S \bar{c}^{2} C_{m_{q}} & a_{4} & =\frac{1}{2 I_{y y}} \rho V^{2} S \bar{c} C_{m_{\alpha}} \\
b & =\frac{1}{2 I_{y y}} \rho V^{2} S \bar{c} C_{m_{\delta_{e}}} & \varepsilon_{\gamma} & =\frac{1}{2 m} \rho V S C_{L_{0}}
\end{aligned}
$$

The controllability matrix $\Upsilon$ given by:

$$
\Upsilon=\left[g, a d_{f} g, a d_{f}^{2} g\right]
$$

is such that:

$$
\Upsilon=\left(\begin{array}{ccc}
0 & 0 & a_{2} b \\
0 & -b & a_{3} b \\
b & -a_{3} b & b\left(a_{3}^{2}+a_{4}\right)
\end{array}\right)
$$

Since, $\operatorname{det}(\Upsilon)=a_{2} b^{3}$, the above system is locally controllable over $\mathbb{R}^{3}$ if and only if $a_{2} \neq 0$ and $b \neq 0$.

\section{CONTROL DESIGN WITH PARAMETER UNCERTAINTY}

Here it is assumed that some uncertainties remain with respect to the main aerodynamic coefficients of the above model. The main control objective is here the tracking of a given flight path angle which changes according to the guidance needs. In order to safely achieve this control objective, a nonlinear adaptive sliding mode control is developed.
The relative degree of the considered output $y=\gamma$ is equal to three:

$$
\begin{gathered}
\dot{y}=\dot{\gamma} \\
=a_{1} \cos (\gamma)+a_{2}(\theta-\gamma)+\varepsilon_{\gamma} \\
y^{(2)}=\gamma^{(2)} \\
=-\frac{a_{1}^{2}}{2} \sin (2 \gamma)-a_{1} \sin (\gamma)\left[a_{2}(\theta-\gamma)+\varepsilon_{\gamma}\right] \\
\quad+a_{2}\left[q-a_{1} \cos (\gamma)-a_{2}(\theta-\gamma)-\varepsilon_{\gamma}\right] \\
y^{(3)}=\gamma^{(3)} \\
=f_{0}+a_{2} f_{1}+a_{2}^{2} f_{2}+\left(a_{2}^{3}+a_{2} a_{4}\right) f_{3}+a_{2} a_{3} f_{4} \\
+a_{2} b \delta_{e}
\end{gathered}
$$

where:

$$
\begin{gathered}
f_{0}=-a_{1}^{2} \varepsilon_{\gamma}\left[\cos ^{2}(\gamma)+\cos (2 \gamma)\right]-a_{1} \varepsilon_{\gamma}^{2} \cos (\gamma) \\
-a_{1}^{3} \cos (\gamma) \cos (2 \gamma) \\
f_{1}=-a_{1}^{2}(\theta-\gamma)\left[\cos ^{2}(\gamma)+\cos (2 \gamma)\right]+a_{1}^{2} \sin (2 \gamma) \\
-2 a_{1} \varepsilon_{\gamma}(\theta-\gamma) \cos (\gamma)+a_{1}\left(2 \varepsilon_{\gamma}-q\right) \sin (\gamma) \\
f_{2}=2 a_{1}(\theta-\gamma) \sin (\gamma)-a_{1}(\theta-\gamma)^{2} \cos (\gamma) \\
+a_{1} \cos (\gamma)-q+\varepsilon_{\gamma} \\
f_{3}=\theta-\gamma \\
f_{4}=q
\end{gathered}
$$

Then, no internal dynamics is associated with this output and (10c) can be rewritten under a linearly parameterized form such as:

$$
h\left[\gamma^{(3)}-f_{0}\right]+\sum_{i=1}^{4} \lambda_{i} f_{i}=\delta_{e}
$$

where:

$$
\begin{aligned}
& h=\frac{1}{a_{2} b} \quad \lambda_{1}=-\frac{1}{b} \quad \lambda_{2}=-\frac{a_{2}}{b} \\
& \lambda_{3}=-\frac{a_{2}^{2}+a_{4}}{b} \quad \lambda_{4}=-\frac{a_{3}}{b}
\end{aligned}
$$

To synthesize the adaptive control law, it is assumed that $f_{0}$ and $f_{i}$ are known nonlinear functions of the state and time; the parameters $h$ and $\lambda_{i}$ are unknown constants. We assume also that the full state vector components are available through the measure, and that the sign of $h$ is known [3].

Now, let us choose a sliding surface $\sigma$ such as:

$$
\begin{gathered}
\sigma=y^{(2)}-v \\
v=\gamma_{d}^{(2)}-k_{1} \dot{z}-k_{2} z
\end{gathered}
$$

with:

$$
z=\gamma-\gamma_{d}
$$

where $z$ represents the tracking error, $\gamma_{d}$ is the desired flight path angle and $k_{1}, k_{2}$ are real positive parameters. 
Now a candidate Lyapunov positive definite function $V_{1}(\sigma)$ can be defined:

$$
\begin{gathered}
V_{1}(\sigma)=\frac{1}{2} \sigma^{2} \\
\dot{V}_{1}(\sigma)=\sigma \dot{\sigma} \\
=\sigma\left[\frac{1}{h}\left(\delta_{e}+h f_{0}-\sum_{i=1}^{4} \lambda_{i} f_{i}\right)-\dot{v}\right]
\end{gathered}
$$

asymptotic Lyapunov stability will be guaranteed if $\dot{V}_{1}(\sigma)=$ $\sigma \dot{\sigma}<0$, for which the control law could be chosen as follows:

$$
\delta_{e}=h\left[\gamma_{d}^{(3)}-k_{1} z^{(2)}-k_{2} \dot{z}-f_{0}\right]+\sum_{i=1}^{4} \lambda_{i} f_{i}-k \sigma
$$

where $k$ is a real positive parameter.

Parameters $h$ and $\lambda_{i}$ are unknown, and they are replaced by their estimates $\hat{h}$ and $\hat{\lambda}_{i}$ respectively and the proposed control law is expressed such as:

$$
\delta_{e}=\hat{h}\left[\gamma_{d}^{(3)}-k_{1} z^{(2)}-k_{2} \dot{z}-f_{0}\right]+\sum_{i=1}^{4} \hat{\lambda}_{i} f_{i}-k \sigma
$$

To get the closed-loop dynamics, let us replace the synthesized control law expression (18) in the time derivative of the sliding surface $\sigma$ :

$$
h \dot{\sigma}+k \sigma=\sum_{i=1}^{4} \tilde{\lambda}_{i} f_{i}+\tilde{h}\left(\dot{v}-f_{0}\right)
$$

with:

$$
\begin{gathered}
\tilde{h}=\hat{h}-h \\
\tilde{\lambda}_{i}=\hat{\lambda}_{i}-\lambda_{i}
\end{gathered}
$$

and these represent the estimation errors related to the controller parameters. The closed-loop dynamics (19) shows that if the estimation errors related to the controller parameters converge to zero, then the tracking error dynamics tend to zero exponentially as shown:

$$
h \dot{\sigma}+k \sigma=0
$$

To synthesize an adaptation mechanism, the positivity and Lyapunov design principle is applied in order to determine the adaptation laws which allow the on-line estimation of the unknown controller parameters $\hat{h}$ and $\hat{\lambda}_{i}$. Consequently another Lyapunov positive definite function $V_{2}\left(\sigma, \tilde{\lambda}_{i}, \tilde{h}\right)$ is introduced:

$$
V_{2}\left(\sigma, \tilde{\lambda}_{i}, \tilde{h}\right)=\frac{1}{2}|h| \sigma^{2}+\frac{1}{2 \eta}\left[\tilde{h}^{2}+\sum_{i=1}^{4} \tilde{\lambda}_{i}^{2}\right]
$$

where $\eta$ denotes the gain adaptation. The idea is to choose $\dot{\hat{h}}$ and $\dot{\hat{\lambda}}_{i}$ such that $\dot{V}_{2}\left(\sigma, \tilde{\lambda}_{i}, \tilde{h}\right) \leqslant 0$. Since:

$$
\begin{aligned}
\dot{V}_{2}\left(\sigma, \tilde{\lambda}_{i}, \tilde{h}\right)= & \frac{|h|}{h} \sigma\left[\sum_{i=1}^{4} \tilde{\lambda}_{i} f_{i}+\tilde{h}\left(\dot{v}-f_{0}\right)-k \sigma\right] \\
& +\frac{1}{\eta}\left[\tilde{h} \dot{\hat{h}}+\sum_{i=1}^{4} \tilde{\lambda}_{i} \dot{\hat{\lambda}}_{i}\right]
\end{aligned}
$$

choosing $\dot{\hat{h}}$ and $\dot{\hat{\lambda}}_{i}$ such as:

$$
\begin{gathered}
\dot{\hat{\lambda}}_{i}=-\eta \operatorname{sgn}(h) \sigma f_{i} \\
\dot{\hat{h}}=-\eta \operatorname{sgn}(h) \sigma\left(\dot{v}-f_{0}\right)
\end{gathered}
$$

then:

$$
\dot{V}_{2}\left(\sigma, \tilde{\lambda}_{i}, \tilde{h}\right)=-|k| \sigma^{2}
$$

and the global tracking convergence of the adaptive control system is guaranteed.

\section{SIMULATION STUDY}

To test the effectiveness of the developed controller, it has been applied to the path angle tracking of a very large, fourengine, passenger jet aircraft for several flight conditions as it is shown in Table 3 below.

The considered aircraft has the following general parameters as it is shown in Table 1:

TABLE I

Aircraft General Parameters

\begin{tabular}{c||c}
\hline Parameter & Value \\
\hline \hline Wing area $\left(\mathrm{m}^{2}\right)$ & 510 \\
Aspect ratio $(\mathrm{AR})$ & 7.0 \\
Mean chord line $\bar{c}(\mathrm{~m})$ & 8.3 \\
Gravity centre & $0.25 \bar{c}$ \\
Total related thrust $(K N)$ & 900 \\
\hline
\end{tabular}

In Table 2. the weight and the inertias of the aircraft during the approach segment and in all other considered flight conditions are shown.

TABLE II

WEIGHT AND INERTIAS

\begin{tabular}{c||c||c}
\hline & Approach & All other flight conditions \\
\hline \hline Weight $(\mathrm{Kg})$ & 250000 & 290000 \\
$I_{x x}\left(K g . \mathrm{m}^{2}\right)$ & $18.6 \times 10^{6}$ & $24.6 \times 10^{6}$ \\
$I_{y y}\left(\mathrm{Kg} . \mathrm{m}^{2}\right)$ & $41.35 \times 10^{6}$ & $45 \times 10^{6}$ \\
$I_{z z}\left(\mathrm{Kg} . \mathrm{m}^{2}\right)$ & $58 \times 10^{6}$ & $67.5 \times 10^{6}$ \\
$I_{x z}\left(\mathrm{Kg} . \mathrm{m}^{2}\right)$ & $1.2 \times 10^{6}$ & $1.32 \times 10^{6}$ \\
\hline
\end{tabular}


TABLE III

FLIGHT CONDITIONS

\begin{tabular}{|c|c|c|c|c|}
\hline parameter & FC1 & FC2 & FC3 & FC4 \\
\hline Height $(m)$ & S.L & 6100 & 6100 & 12200 \\
\hline Mach & 0.198 & 0.5 & 0.5 & 0.8 \\
\hline$V\left(m \cdot s^{-1}\right)$ & 67 & 158 & 250 & 250 \\
\hline $\bar{q}\left(N . m^{-2}\right)$ & 2810 & 8667 & 24420 & 9911 \\
\hline$\alpha_{0}($ degree $)$ & 8.5 & 6.8 & 0 & 4.6 \\
\hline
\end{tabular}

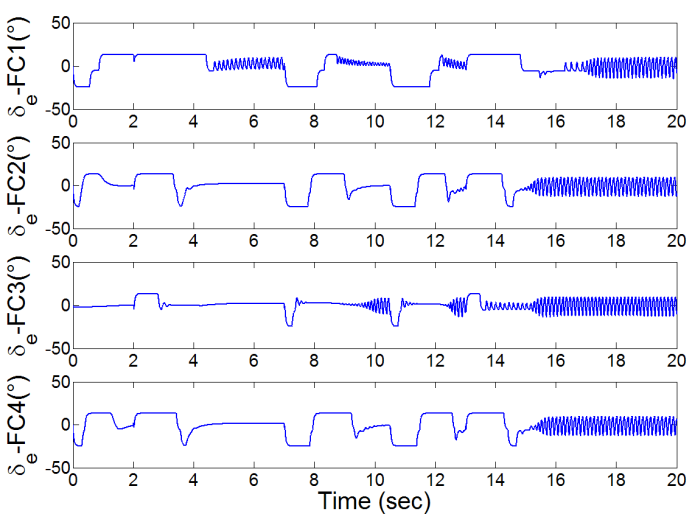

Fig. 1. Control Input

Fig. 1 shows the response due to the elevator deflection since it is considered that it follows saturated first order dynamics in order to respect the physical limitations of the considered actuator. Obtained results show chattering phenomenon often present while sliding mode control is applied.

This phenomenon can create hazardous consequences both on the considered actuator and on the flight safety.

Fig. 2 displays desired flight path tracking of the aircraft for different flight conditions, desired flight path is chosen as a set of several straight lines with different slopes; this choice can be considered a hard test for the robustness of

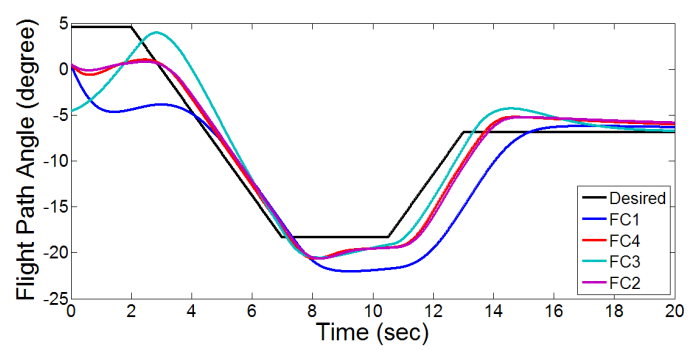

Fig. 2. Desired Flight Path Tracking

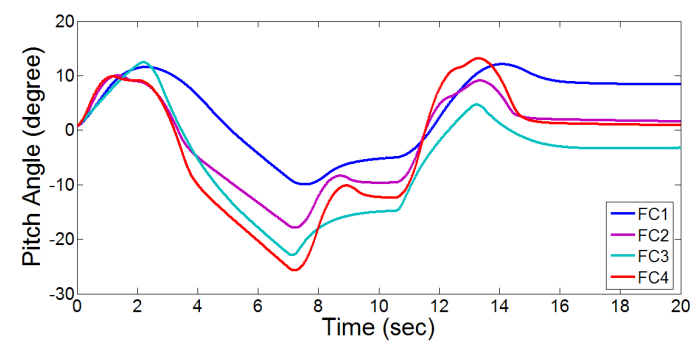

Fig. 3. Pitch Angle Evolution

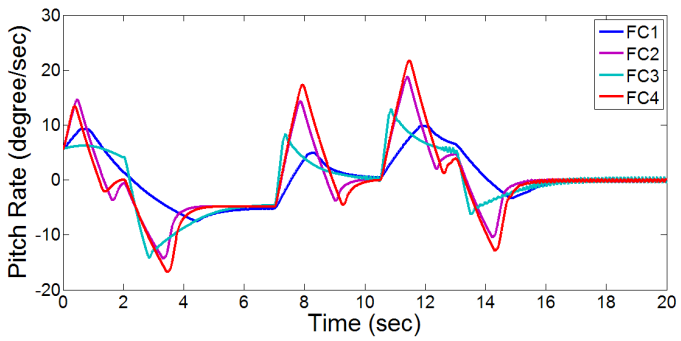

Fig. 4. Pitch Rate Evolution

the proposed controller in real life. The obtained tracking results show that a good path angle tracking performance is achieved.

Fig. 3 and Fig. 4 show the evolution of the pitch angle and the pitch rate according to the considered flight conditions.

The angle of attack remains among the main variables affecting the flight safety for civil aviation. It can be seen in Fig. 5 that the behavior of the angle of attack remains within an acceptable range for considered flight conditions.

To deal with chattering phenomenon, we have added to the desired flight path angle defined above a second order model reference to get a smooth reference input and to considerably decrease the chattering phenomenon since this model reference also has the role of a filter as it is shown in Fig. 6 and Fig. 10 below.

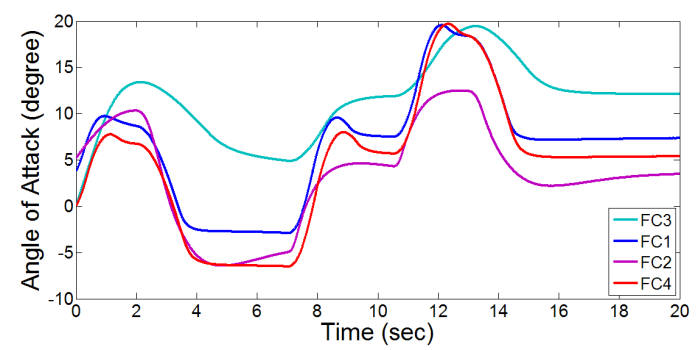

Fig. 5. Angle of Attack Evolution 


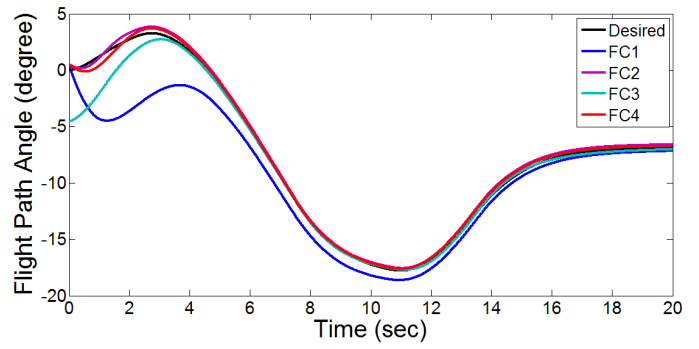

Fig. 6. Desired Flight Path Tracking with Model-Reference

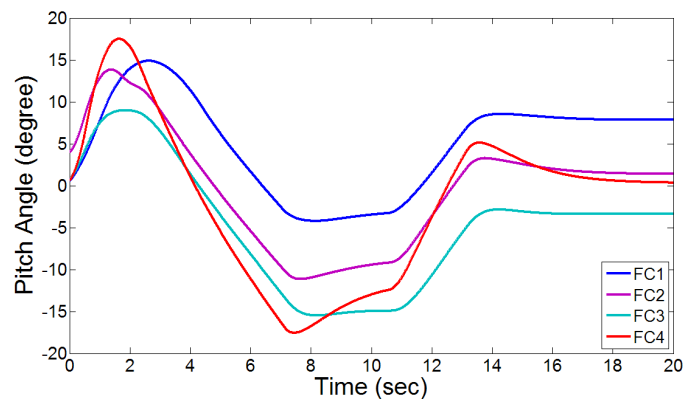

Fig. 7. Pitch Angle Evolution with Model-Reference

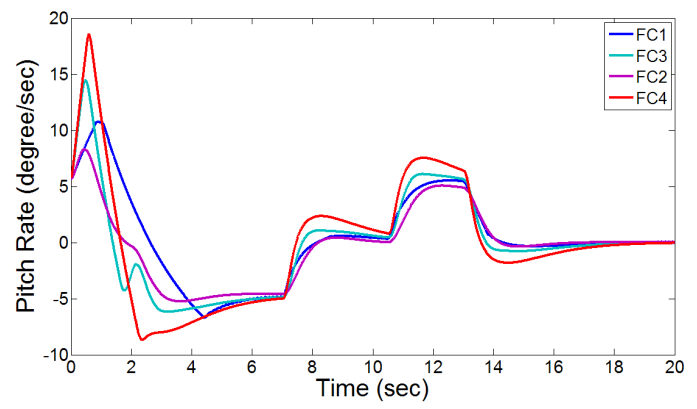

Fig. 8. Pitch Rate Evolution with Model-Reference

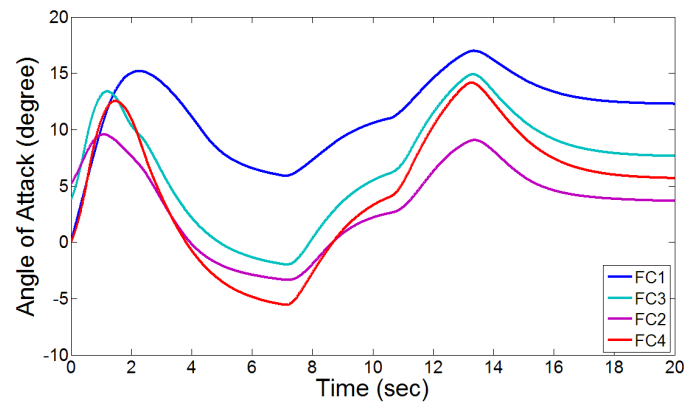

Fig. 9. Angle of Attack Evolution with Model-Reference

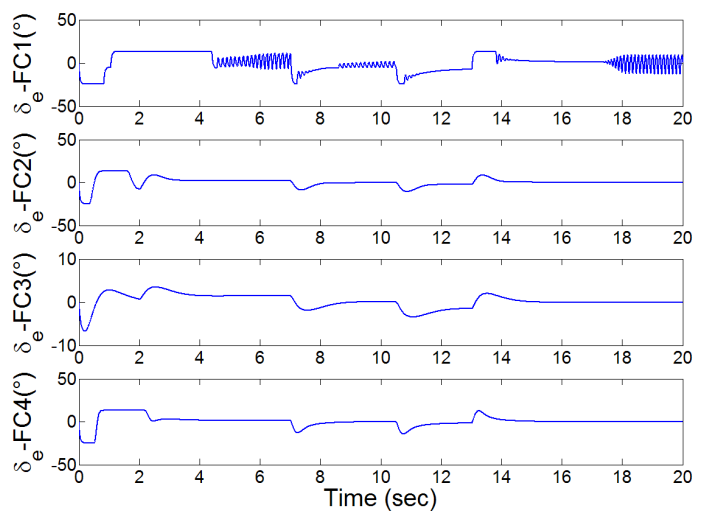

Fig. 10. Control Input with Model-Reference

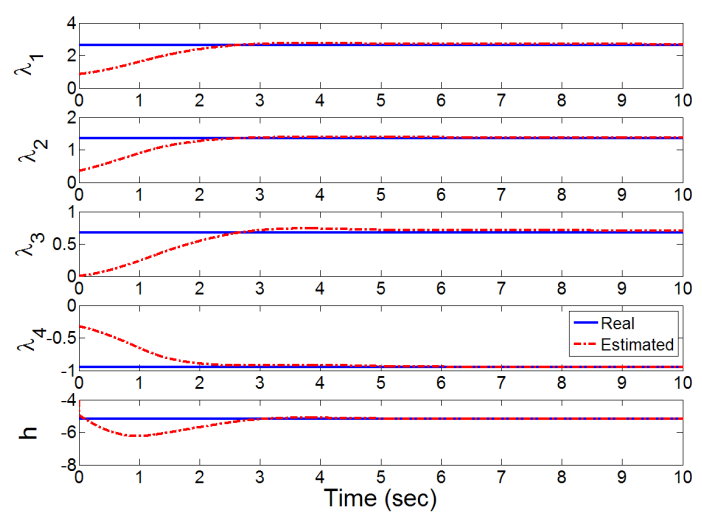

Fig. 11. Controller Parameters Estimation Related to FC1

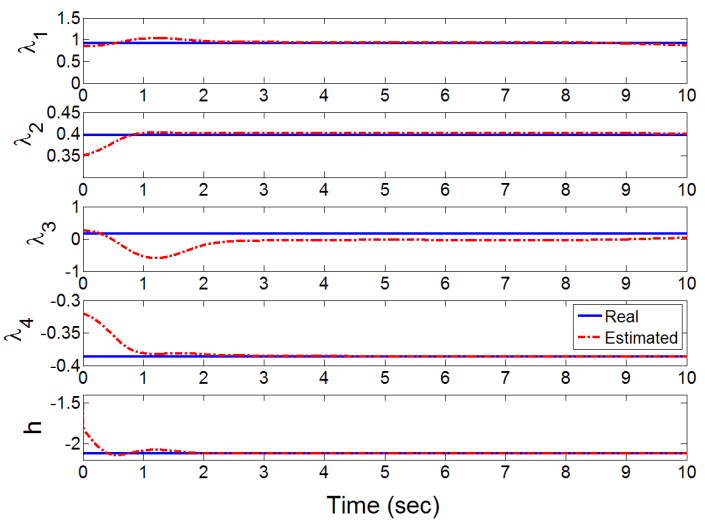

Fig. 12. Controller Parameters Estimation Related to FC2 

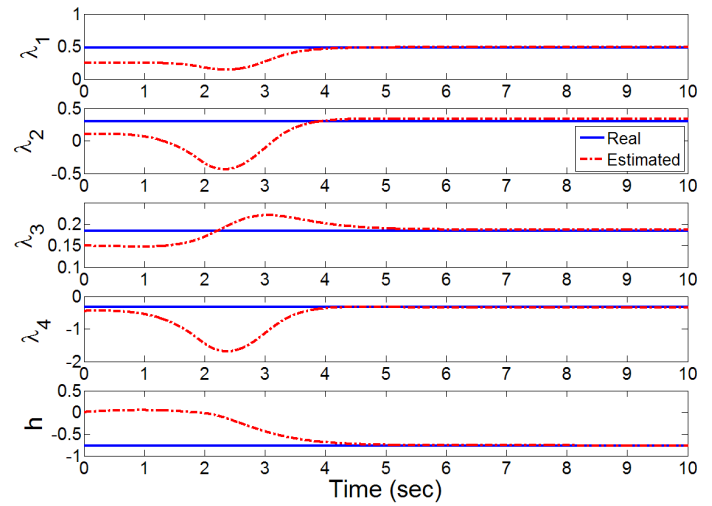

Fig. 13. Controller Parameters Estimation Related to FC3

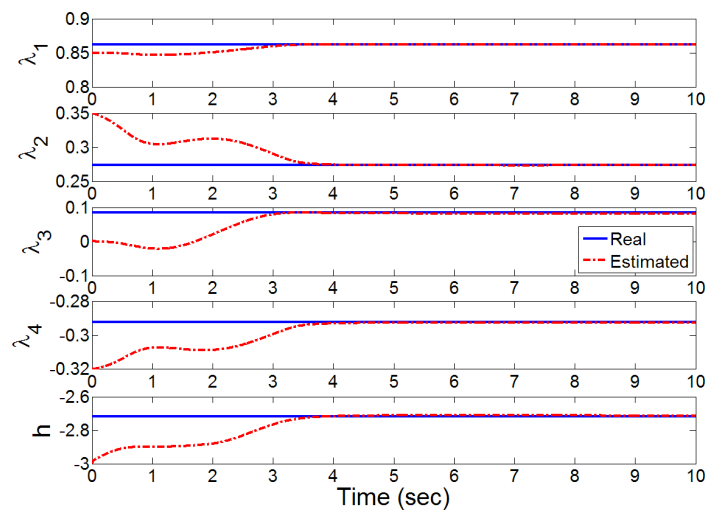

Fig. 14. Controller Parameters Estimation Related to FC4

Fig. 11, Fig. 12, Fig. 13 and Fig. 14 display the estimation of the considered controller parameters $\hat{h}$ and $\hat{\lambda}_{i}$ according to the applied flight conditions FC1, FC2, FC3 and FC4.

The obtained simulation results show acceptable estimation performances.

\section{CONCLUSION}

In this paper, an adaptive flight path control for transportation aircraft is considered while the controllability condition is checked.

Control design is a hybridization between a nonlinear dynamic inversion method and adaptive sliding mode control approach; developed controller had ensured asymptotic Lyapunov stability and guaranteed robustness against the system parameters uncertainties.

Since direct adaptive control design approach is used, an adaptation mechanism is developed based on the positivity and Lyapunov principle design in order to synthesize the adaptation laws which allow the estimation of the controller parameters and to guarantee the exponential convergence of the tracking error dynamics.

Despite the use of saturated first order dynamics for the control input in order to respect the physical limitations of the considered actuator. Desired flight path tracking is performed, chattering phenomenon is considerably decreased and angle of attack is maintained within an acceptable range.

To test the robustness of the proposed control design we have applied synthesized control law to several flight conditions. Simulation results show satisfactory performances.

Adaptive control can provide even some fault tolerance against unforeseen failures and improve the aircraft chances of survivability under adverse conditions. In perspective, we would like to develop adaptive controllers which can deal with failures and also with dynamic parameters.

\section{REFERENCES}

[1] T. Lee and K. Youdan, Nonlinear Adaptive Flight Control using Backstepping and Neural Networks Controller, Journal of Guidance, Control and Dynamics, vol. 24, July-August 2001.

[2] W. Mackunis, P.M. Patre, M.K. Kaiser and W. E. Dixon, Asymptotic Tracking for Aircraft via Robust and Adaptive Dynamic Inversion Methods, IEEE transaction on control systems technology, 2010.

[3] I.J.-J. Slotine and L. Weiping, Applied Nonlinear Control, Prentice Hall, Upper Saddle River, NJ; 1991.

[4] M. Sharma, "Flight Path Angle Control via Neuro-Adaptive Backstepping", 4451, Proc. AIAA Guidance, Navigation, and Control Conference, Monterey, Canada, Aug. 2002.

[5] L. duan, W. Lu, F. Mora-Camino and T. Miquel, ’Flight Path Tracking Control of a Transportation Aircraft: Comparison of two Nonlinear Design Approaches", 25th Digital Avionics Systems Conference IEEE/AIAA, 2006.

[6] O. Harkegard, S. Torkel Glad, "a Backstepping Design for Flight Path Angle Control", proceedings of the 39th IEEE Conference on Decision and Control, 2000.

[7] W. Mackunis, P.M. Patre, M.K. Kaiser and W. E. Dixon, "Asymptotic Tracking for Aircraft via an Uncertain Dynamic Inversion Method", American Control Conference, Seattle, Washington, USA June 11-13, 2008.

[8] Z. Yu, G. Fan, and J. Yi, "Indirect Adaptive Flight Control Based on Nonlinear Inversion", Proceedings of the IEEE International Conference on Mechatronics and Automation, cahngchun, china, august 9-12, 2009.

[9] A. Dorobantu, P. Seiler, and G. Balas, "Nonlinear Analysis of Adaptive Flight Control Laws", AIAA Guidance, Navigation, and Control Conference, Toronto, Ontario Canada, 2-5 August 2010.

[10] K. Rajagopal, S.N. B, "Robust Adaptive Control of a General Aviation Aircraft", AIAA Guidance, Navigation, and Control Conference, Toronto, Ontario Canada, 2-5 August 2010.

[11] N. Sahjendra Singh, M. L.Steinberg and Anthony B. Page, "Variable Structure and Nonlinear Adaptive Flight Path Control", Proceedings of the American Control Conference, Anchorage, AK May 8-10, 2002.

[12] T. Wang, W. Xie and Y. Zhang, "Sliding Mode Reconfigurable Control with Application to Longitudinal Control of Boeing 747", AIAA Guidance, Navigation, and Control Conference, Toronto, Ontario Canada, 2-5 August 2010. 